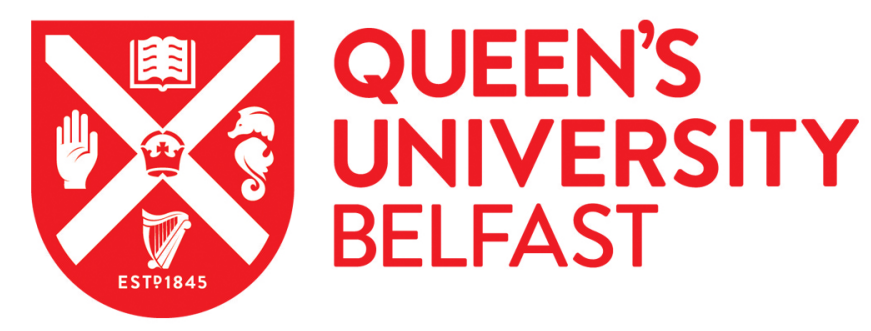

\title{
All cause and cardiovascular mortality in African migrants living in Portugal: evidence of large social inequalities
}

Harding, S., Teyhan, A., Rosato, M., \& Santana, P. (2008). All cause and cardiovascular mortality in African migrants living in Portugal: evidence of large social inequalities. European Journal of Cardiovascular Prevention and Rehabilitation, 15(6), 670-676. https://doi.org/10.1097/HJR.0b013e32830fe6ce

Published in:

European Journal of Cardiovascular Prevention and Rehabilitation

Queen's University Belfast - Research Portal:

Link to publication record in Queen's University Belfast Research Portal

\section{General rights}

Copyright for the publications made accessible via the Queen's University Belfast Research Portal is retained by the author(s) and / or other copyright owners and it is a condition of accessing these publications that users recognise and abide by the legal requirements associated with these rights.

Take down policy

The Research Portal is Queen's institutional repository that provides access to Queen's research output. Every effort has been made to ensure that content in the Research Portal does not infringe any person's rights, or applicable UK laws. If you discover content in the Research Portal that you believe breaches copyright or violates any law, please contact openaccess@qub.ac.uk. 


\title{
All cause and cardiovascular mortality in African migrants living in Portugal: evidence of large social inequalities Seeromanie Harding ${ }^{a}$, Alison Teyhan ${ }^{a}$, Michael Rosato ${ }^{b}$ and Paula Santana ${ }^{c}$
}

\author{
${ }^{a}$ Medical Research Council, Social and Public Health Sciences Unit, Glasgow, Scotland, bDepartment of \\ Epidemiology and Public Health, The Queen's University of Belfast, Belfast, Northern Ireland, UK and \\ ${ }^{\circ}$ Geographical Studies Institute, University of Coimbra, Coimbra, Portugal
}

Received 29 October 2007 Accepted 9 July 2008

\begin{abstract}
Aim To examine cardiovascular mortality of African migrants in Portugal in relation to socio-economic status.
Method Data from death registrations, 1998-2002, and the 2001 Census were used to derive standardized death rates by country of birth and occupational class/marital status.

Results Compared with native Portuguese, African migrants had higher mortality for all causes, circulatory disease, coronary heart disease and stroke. There was considerable heterogeneity among Africans with Cape Verdeans having higher mortality than Angolans or Mozambiquans. Class differences in mortality were generally greater for African than for Portuguese men. Although the coronary heart disease mortality rate among Africans in a manual class was twice that of those in a nonmanual class, there was no class difference for Portuguese men. Marital status was associated with 2-3-fold differences in mortality rates in both Africans and Portuguese. A larger proportion of Africans were not married which accounted for some of the excess mortality.

Conclusion Adverse cardiovascular mortality experience of African migrants is associated with socio-environmental factors. Investigating how best to achieve risk reduction in Africans should be a public health priority in Portugal. Eur $J$ Cardiovasc Prev Rehabil 15:670-676 @ 2008 The European Society of Cardiology
\end{abstract}

European Journal of Cardiovascular Prevention and Rehabilitation 2008, 15:670-676

Keywords: African migrants, cardiovascular mortality, Portugal, social inequalities

\section{Background}

Populations of African origin in the UK, the US and the Caribbean have high levels of hypertension, stroke and diabetes and therapeutic responses differ from those of European ancestry [1-5]. Relatively low coronary heart disease (CHD) mortality is also known. Recent migration of people from West Africa to western and southern European Union (EU) countries offers the opportunity to examine the influence of different social environments on cardiovascular disease in Africans. Cardiovascular health is strongly patterned by socio-economic factors in western, developed countries [6], but the extent to which differences in the social distribution of risk contribute to ethnic disparities is still debated.

Correspondence to Seeromanie Harding, Medical Research Council, Social and Public Health Sciences Unit, 4 Lilybank Gardens, Glasgow, G12 8RZ, Scotland, UK

E-mail: seeromanie@sphsu.mrc.ac.uk
Portugal, one of the main receiving countries in the South, occupies an unusual historical position compared with other receiving countries such as the UK or France. Though relatively poor compared with most western or southern EU countries, Portugal has undergone rapid societal transformation since its political revolution in 1974 and EU membership in 1986, with dramatic improvements in living standards [7]. Stroke mortality in Portugal, although reducing dramatically over the past two decades, remains higher than that for most western European countries [8]. In contrast, CHD mortality is low and similar to Spain and Italy, also countries with historically low CHD rates. Most Africans in Portugal originate from its excolonies, principally Cape Verde, Angola and Mozambique, with peak migration occurring in the late 1970s and early 1980s following their political independence. To our knowledge this is the first study to examine cardiovascular mortality of Africans in Portugal. 
Cardiovascular risk in Africans has been linked to urbanization. Studies in the 1970s found low prevalence of hypertension (less than 10\%) in rural areas of Ghana [9], Nigeria [10] and Lesotho [11], and recent studies in Cameroon [12] and Ghana [13] found that although prevalence may be rising in rural areas, it remains lower than in urban areas. Prevalence in west African origin Caribbean populations is intermediate between those in west Africa and the UK, suggesting that behavioural change associated with societal transition is a contributory factor [5,14]. In England and Wales, CHD mortality among Jamaican women, traditionally lower than the national average, was higher for the first time in the late 1990s [15]. A similar crossover of death rates has been observed in the US for Black Americans. Data on changes in behavioural risk factors is patchy. In Kenya, those who moved to Nairobi had higher urinary sodium-potassium ratios than those who remained in rural areas, suggesting higher salt intake among those who moved [16]. In the UK, British-born Black Caribbeans have higher caloric intake from fat, lower levels of high-density lipoprotein and smoke more than foreign-born Black Caribbeans [17].

\section{Methods}

The Instituto Nacional de Estatística in Portugal provided anonymized death records for 1998-2002, and tabulated population data from the 2001 Census. Deaths and populations-at-risk were derived by country of birth and 5-year age groups, with analyses based on those aged 25-64 years. This age restriction was owing to small numbers of deaths at younger ages and to the potential inaccuracies in denominator data at older ages from return migration to home countries. We identified people born in Portugal $(n=5093910)$, referred to hereafter as Portuguese, and those born in countries with mainly Black African populations (Angola $=140770$; Mozambique $=64927 ;$ Cape Verde $=32$ 871; Guinea $=235$; Equatorial Guinea $=50$; Guinea Bissau $=14871 ;$ St Tome and Principe $=8246$ ), referred to hereafter as Africans. People born in other African countries and in Brazil were excluded owing to small number of deaths. Marital status was classified as not married or married, and occupational class as nonmanual, manual or unclassified. Nonmanual included higher administrative, intellectual or technical workers and manual included sellers/traders, agricultural or other industrial workers, labourers or unqualified workers. Two tables containing denominators from the census were supplied; one with age by country of birth, sex and marital status and another with age by country of birth, sex and occupational class. A single table with marital categories within occupational classes was not allowed because of potential identification of individuals, preventing analysis of the joint effect of these variables on mortality. Analysis of mortality by occupational class was limited to men only as a large number of deaths among women were not classified to an occupational class.
Deaths between 1998 and 2000 were classified to the 9th International Classification of Disease (3900-4599 for circulatory disease; 4100-4149 for CHD; 4300-4389 for stroke) and for those between 2001 and 2003 to ICD10 (I00-I99 for circulatory disease; I20-I25 for CHD; I60 I69 for stroke). Directly standardized rates adjusted to the European standard population 2000, rate ratios using the rate of the Portuguese as a reference rate and $95 \%$ confidence intervals were derived [18,19]. Rates were derived for all Africans and for the three largest groups (Angolans, Mozambiquans and Cape Verdeans), where at least 20 deaths were recorded in each 10 -year age group. Poisson regression models were used to examine the contribution of occupational class and marital status to the mortality differences between African migrants and those born in Portugal. Similar data for African migrants to England and Wales were used to derive corresponding death rates and rate ratios, which enabled comparisons with Africans in Portugal.

\section{Results \\ Mortality from all causes, coronary heart disease and stroke}

Among both Portuguese and Africans, circulatory disease accounted for about $20 \%$ of deaths and among women there were more deaths from stroke than CHD. Death rates were higher for Africans than for Portuguese (Fig. 1). Among African men, Cape Verdeans had higher all cause and circulatory mortality than Angolans or Mozambiquans, and higher CHD and stroke mortality than Angolans. Among African women, Cape Verdeans had higher all cause mortality than Angolans or Mozambiquans, and higher CHD mortality than Mozambiquans.

\section{Mortality by occupational class and marital status}

A larger proportion among the Africans was classified as not married (53\% of men; $55 \%$ of women) or as nonmanual (37\% of men) than among the Portuguese (not married $-25 \%$ of men, $27 \%$ of women; nonmanual $27 \%$ of men). African men were also more likely to be classified to an occupational class (84\% Africans compared with $80 \%$ Portuguese).

Class (men) and marital status were significant correlates of mortality for both Africans and Portuguese (Table 1). A notable exception was a lack of difference in CHD mortality by class among Portuguese men (Table 1). Class differences in mortality were generally greater for Africans than for Portuguese. By marital status, a greater difference in mortality was seen only for all cause mortality among African women. It is striking that in every class and marital status category, the rates for Africans were higher than for Portuguese. Adjusting for marital status reduced the rate ratios shown in Fig. 1, by about $10-12 \%$ for women and 16-17\% for men. Adjusting for class made little difference. 
Fig. 1

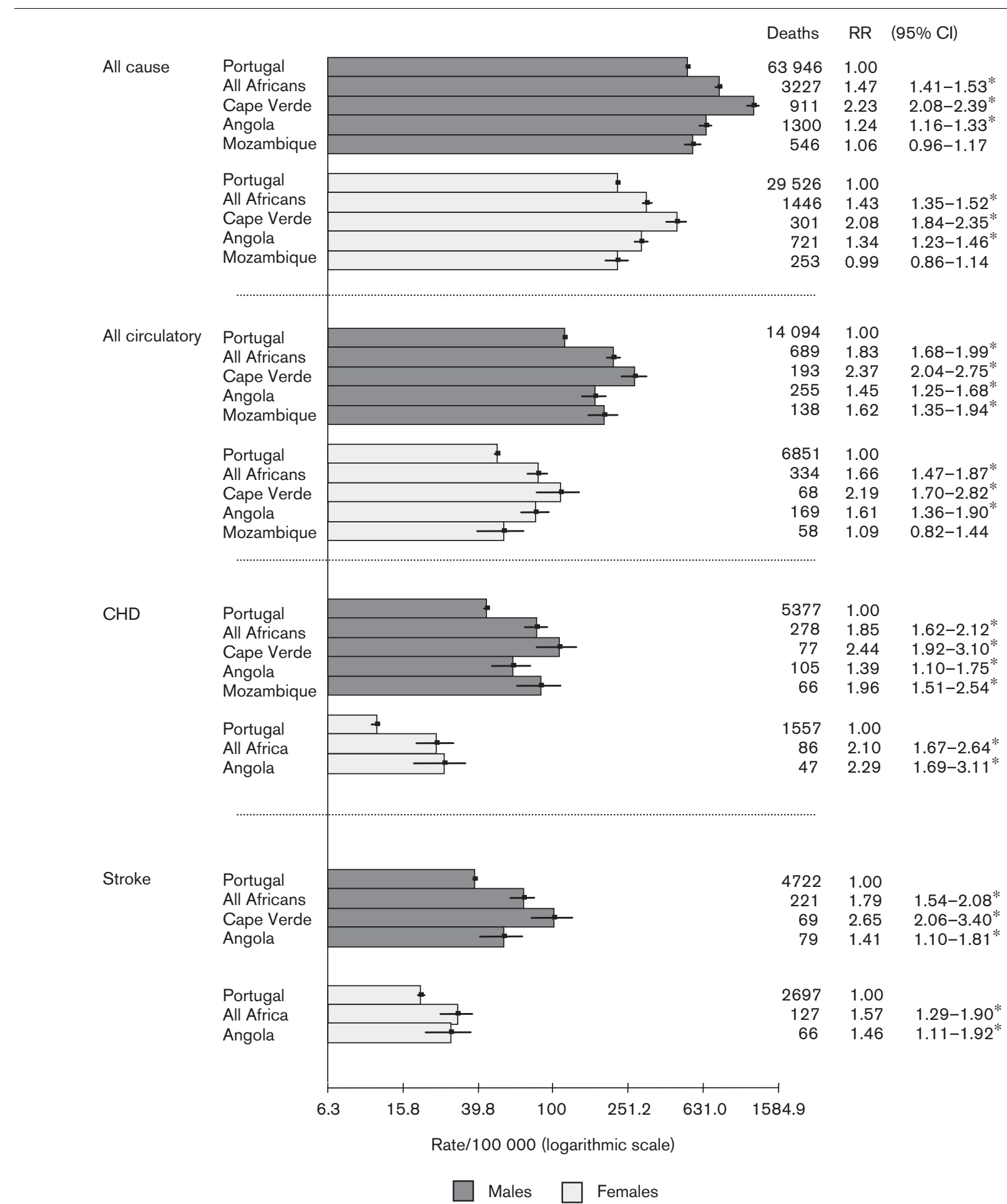

Death rates (adjusted to European standard population. $* P<0.05$ compared with rate for those born in Portugal), rate ratios (RR) and $95 \%$ confidence intervals (Cl) for African migrants and those born in Portugal, ages 25-64 years. Portugal 1998-2002. CHD, coronary heart disease.

\section{Effect of class and marital status on mortality of Cape Verdeans, Angolans and Mozambiquans}

Cape Verdeans were more socially disadvantaged than Angolans or Mozambiquans. They were less likely to be in a nonmanual class ( $10 \%$ of men) or married ( $46 \%$ of men, $46 \%$ of women) than Angolans (41\% from a nonmanual class; and $54 \%$ of men and $57 \%$ of women married) and Mozambiquans (52\% of men from a nonmanual class; $61 \%$ 
Table 1 Death rates ${ }^{a}$, rate ratios (RR) and $95 \%$ confidence intervals $(\mathrm{Cl})$ by marital status and, separately, by occupational class (for men only) for both African migrants and people born in Portugal, ages 25-64 years. Portugal 1998-2002

\begin{tabular}{|c|c|c|c|c|c|c|c|c|}
\hline & \multicolumn{3}{|c|}{ Born in Portugal } & \multicolumn{3}{|c|}{ African migrants in Portugal } & \multirow[b]{2}{*}{$\mathrm{RR}^{\mathrm{b}}$} & \multirow[b]{2}{*}{$95 \% \mathrm{Cl}$} \\
\hline & Deaths & Rate/RR & $95 \% \mathrm{Cl}$ & Deaths & Rate/RR & $95 \% \mathrm{Cl}$ & & \\
\hline \multicolumn{9}{|l|}{ Men } \\
\hline \multicolumn{9}{|l|}{ All cause } \\
\hline Nonmanual & 8192 & 300.9 & $294.1-307.8$ & 542 & 391.4 & $349.7-433.0$ & 1.30 & $1.17-1.45$ \\
\hline Manual & 26053 & 450.4 & $444.7-456.0$ & 1535 & 805.7 & $750.2-861.2$ & 1.79 & $1.67-1.92$ \\
\hline Unclassified & 29701 & 956.6 & $943.3-969.9$ & 1150 & 1266.9 & $1190.3-1343.4$ & 1.32 & $1.24-1.41$ \\
\hline RR manual versus nonmanual & & 1.50 & $1.46-1.54$ & & 2.06 & $1.81-2.34$ & & \\
\hline Married & 41796 & 404.8 & $400.9-408.7$ & 1180 & 496.5 & $465.8-527.1$ & 1.23 & $1.16-1.31$ \\
\hline Not married & 22082 & 1069.7 & $1054.6-1084.8$ & 2040 & 1322.4 & $1243.6-1401.1$ & 1.24 & $1.17-1.32$ \\
\hline RR not married versus married & & 2.64 & $2.59-2.69$ & & 2.66 & $2.44-2.90$ & & \\
\hline RR adjusted for class & & & & & 1.47 & $1.42-1.53$ & & \\
\hline $\mathrm{RR}$ adjusted for marital status & & & & & 1.18 & $1.14-1.22$ & & \\
\hline \multicolumn{9}{|l|}{ Circulatory } \\
\hline Nonmanual & 2010 & 78.2 & $74.6-81.8$ & 136 & 116.0 & $92.2-139.8$ & 1.48 & $1.20-1.83$ \\
\hline Manual & 4753 & 89.4 & $86.8-92.1$ & 303 & 230.2 & $197.1-263.2$ & 2.57 & $2.22-2.98$ \\
\hline Unclassified & 7331 & 188.8 & $183.5-194.2$ & 250 & 290.9 & $253.3-328.4$ & 1.54 & $1.35-1.76$ \\
\hline RR manual versus nonmanual & & 1.14 & $1.08-1.20$ & & 1.98 & $1.54-2.54$ & & \\
\hline Married & 9963 & 94.1 & $92.2-95.9$ & 315 & 147.1 & $129.8-164.3$ & 1.56 & $1.38-1.76$ \\
\hline Not married & 4120 & 237.8 & $230.3-245.3$ & 370 & 365.9 & $320.2-411.7$ & 1.54 & $1.35-1.75$ \\
\hline $\mathrm{RR}$ not married versus married & & 2.53 & $2.44-2.63$ & & 2.49 & $2.11-2.94$ & & \\
\hline RR adjusted for class & & & & & 1.82 & $1.69-1.97$ & & \\
\hline RR adjusted for marital status & & & & & 1.49 & $1.38-1.61$ & & \\
\hline \multicolumn{9}{|l|}{$\mathrm{CHD}$} \\
\hline Nonmanual & 959 & 36.9 & $34.4-39.3$ & 68 & 55.4 & $39.2-71.6$ & 1.50 & $1.11-2.02$ \\
\hline Manual & 1869 & 34.9 & $33.3-36.6$ & 120 & 87.1 & $67.4-106.8$ & 2.50 & $1.98-3.15$ \\
\hline Unclassified & 2549 & 67.3 & $64.1-70.5$ & 90 & 110.5 & $86.8-134.1$ & 1.64 & $1.32-2.04$ \\
\hline RR manual versus nonmanual & & 0.95 & $0.88-1.03$ & & 1.57 & $1.09-2.27$ & & \\
\hline Married & 3843 & 36.5 & $35.3-37.6$ & 129 & 55.0 & $44.7-65.2$ & 1.51 & $1.25-1.82$ \\
\hline Not married & 1531 & 90.3 & $85.7-95.0$ & 148 & 150.9 & $121.7-180.0$ & 1.67 & $1.37-2.04$ \\
\hline RR not married versus married & & 2.47 & $2.33-2.62$ & & 2.74 & $2.11-3.53$ & & \\
\hline $\mathrm{RR}$ adjusted for class & & & & & 1.86 & $1.65-2.10$ & & \\
\hline $\mathrm{RR}$ adjusted for marital status & & & & & 1.57 & $1.39-1.77$ & & \\
\hline \multicolumn{9}{|l|}{ Stroke $^{\mathrm{c}}$} \\
\hline Nonmanual & 514 & 20 & $18.1-21.8$ & - & & & - & \\
\hline Manual & 1641 & 31.1 & $29.6-32.7$ & 106 & 79.0 & $59.9-98.0$ & 2.54 & $1.99-3.25$ \\
\hline Unclassified & 2567 & 62.7 & $59.6-65.7$ & 83 & 99.9 & $77.5-122.2$ & 1.59 & $1.26-2.00$ \\
\hline $\mathrm{RR}$ manual versus nonmanual & & 1.56 & $1.41-1.73$ & & 3.39 & $2.08-5.53$ & & \\
\hline Married & 3375 & 31.7 & $30.7-32.8$ & 98 & 45.8 & $36.2-55.5$ & 1.44 & $1.16-1.78$ \\
\hline Not married & 1342 & 78.5 & $74.2-82.8$ & 122 & 128.2 & $101.0-155.5$ & 1.63 & $1.31-2.03$ \\
\hline RR not married versus married & & 2.48 & $2.33-2.65$ & & 2.80 & $2.09-3.75$ & & \\
\hline RR adjusted for class & & & & & 1.85 & $1.62-2.12$ & & \\
\hline RR adjusted for marital status & & & & & 1.49 & $1.30-1.71$ & & \\
\hline \multicolumn{9}{|l|}{ Women } \\
\hline \multicolumn{9}{|l|}{ All cause } \\
\hline Married & 18726 & 184.5 & $181.8-187.1$ & 539 & 213.1 & $193.4-232.9$ & 1.16 & $1.06-1.27$ \\
\hline Not married & 10778 & 333.2 & $326.7-339.6$ & 904 & 458.1 & $424.7-491.5$ & 1.37 & $1.27-1.48$ \\
\hline RR not married versus married & & 1.81 & $1.77-1.85$ & & 2.15 & $1.91-2.42$ & & \\
\hline RR adjusted for marital status & & & & & 1.32 & $1.25-1.39$ & & \\
\hline \multicolumn{9}{|l|}{ Circulatory } \\
\hline Married & 4182 & 40.7 & $39.5-41.9$ & 136 & 59.5 & $48.7-70.4$ & 1.46 & $1.21-1.76$ \\
\hline Not married & 2668 & 79.6 & $76.5-82.7$ & 197 & 116.4 & $98.8-134.0$ & 1.46 & $1.25-1.71$ \\
\hline RR not married versus married & & 1.96 & $1.86-2.06$ & & 1.96 & $1.55-2.47$ & & \\
\hline $\mathrm{RR}$ adjusted for marital status & & & & & 1.54 & $1.38-1.72$ & & \\
\hline $\mathrm{CHD}^{\mathrm{c}}$ & & & & & & & & \\
\hline Married & 937 & 9.1 & $8.5-9.7$ & - & & & - & \\
\hline Not married & 620 & 18.4 & $17.0-19.9$ & 50 & 33.4 & $23.6-43.2$ & 1.82 & $1.34-2.47$ \\
\hline RR not married versus married & & 2.02 & $1.82-2.24$ & & 2.00 & $1.27-3.14$ & & \\
\hline $\mathrm{RR}$ adjusted for marital status & & & & & & & & \\
\hline \multicolumn{9}{|l|}{ Stroke } \\
\hline Married & 1682 & 16.4 & $15.6-17.2$ & 52 & 22.1 & $15.5-28.6$ & 1.35 & $1.00-1.82$ \\
\hline Not married & 1015 & 30.5 & $28.5-32.4$ & 75 & 43.8 & $33.1-54.6$ & 1.44 & $1.12-1.86$ \\
\hline RR not married versus married & & 1.86 & $1.72-2.02$ & & 1.98 & $1.36-2.88$ & & \\
\hline $\mathrm{RR}$ adjusted for marital status & & & & & 1.48 & $1.24-1.78$ & & \\
\hline
\end{tabular}

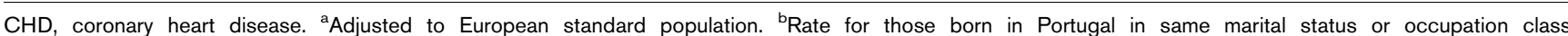
category $=$ baseline. ${ }^{\text {C'-' }}$ where number of deaths $<40$.

of men and $60 \%$ of women married). Adjustment for these indicators reduced mortality differences relative to the Portuguese. All cause mortality rate ratios adjusted for marital status were as follows: Cape Verdeans $-1.73(95 \%$ $\mathrm{CI}=1.62-1.85)$ and $1.87(1.67-2.10)$ for men and women, respectively; Angolans - 1.04 (0.98-1.09) and 
1.25 (1.16-1.35); and Mozambiquans - 0.88 (0.81-0.96) and $0.92(0.81-1.04)$. The corresponding rate ratios for circulatory disease were as follows: Cape Verdeans -1.93 (1.67-2.22) and 2.01 (1.58-2.55) for men and women, respectively; Angolans - $1.26(1.12-1.43)$ and $1.51(1.30$ 1.76); and Mozambiquans - $1.28(1.08-1.52)$ and 1.05 $(0.81-1.37)$.

\section{Discussion}

The relatively poorer health of African migrants to Portugal is not unexpected given the history of underdevelopment and poor health indices of Portugal's excolonies. Low income per capita figures in these countries reflect widespread post-independence economic poverty. Long civil wars in Angola and Mozambique following independence have disrupted societal development. In 2005, life expectancy was 40.7 years in Angola and 41.9 years in Mozambique [20]. Corresponding figures for infant mortality were 139 and 101 per 1000 live births. Cape Verde, on the other hand, has not had civil wars, but repeated droughts during the second half of the 20th century have caused significant hardship and prompted large-scale emigration. Life expectancy (70.2 years) and infant mortality (30/1000 live births) are better than in Angola and Mozambique.

A comparison with the British picture is informative. The relatively higher CHD mortality of African migrants in Portugal is partly because of the low level of CHD mortality of those born in Portugal (Fig. 2). Africans in Portugal do not seem to have any extra benefit, however, from living in a low CHD mortality environment. African men in Portugal have higher CHD death rates than west African men in England and Wales, and also higher stroke death rates than west African and Jamaican men. West Africans in the UK are mainly from Nigeria and Ghana [21], countries that are poor compared with western countries, but which have not been recently disrupted by protracted civil wars or natural disasters. Jamaicans in Britain are largely of west African ancestry, having descended from slaves mainly from Nigeria and Ghana. To some extent, Cape Verdeans share some historic parallels with Caribbeans. The slave trade between Senegal and Sierra Leone in the 15th and 16th centuries provided much of the original population of Cape Verde. Arguably, over generations these historical processes (slavery, post-emancipation poverty) have played a role in shaping the cardiovascular risk of Africans via both developmental pathways (e.g. in-utero and post-natal growth) and social customs (e.g. diet).

The extent to which socio-environmental factors contribute to ethnic differences in cardiovascular health is a long debated issue, partly unresolved due to the lack of relevant data. Cross-sectional measures of social position are inadequate, as they cannot capture duration of exposure [22]. The measurement of social position among migrants is complicated by difficulties in using educational qualifications and experience in the host country, as underemployment and deskilling are common immediately after migration [23]. Our findings are somewhat different from those reported in the UK, where migrant mortality seemed unrelated to occupational class before the 1990s [24,25]. The higher mortality of Africans compared with those born in Portugal in every marital or class category may reflect residual confounding from unmeasured factors [26,27]. Susceptibility due to developmental experiences in early life is possible, but the question still remains as to whether the higher mortality after adjustment for class or marital status is because of greater exposure to unmeasured aspects of social inequality in Portugal.

The National Health Survey in Portugal included Africans for the first time in 2006 but the sample was small (207 Africans). The data suggest less overweight and smoking among Africans than those born in Portugal (data held by authors) [28]. Differential access to health care cannot be ruled out as a key contributor to the disparities in mortality. Hypertension is a risk factor for all cardiovascular disease, but mainly for stroke. Its prevalence in Portugal in 2003 was $50 \%$ in men and $39 \%$ in women [29], similar or lower than many European countries [30]. Levels of control of hypertension are low ( $7 \%$ for men and $11 \%$ for women [29]) and it is possible that these issues have greater relevance for Africans, particularly poor Africans, than those born in Portugal. Africans live mainly in deprived metropolitan areas and poor access to prevention and treatment programmes in these areas is not implausible [7,31].

These findings are subject to the usual limitations of cross-sectional data, notably misclassification of country of birth at census or death certification, and the potential for confounding caused by health selection on migration. Higher proportions of African men were classified to both an occupational class and a nonmanual class, suggesting that migrants were more skilled and healthier than those left behind in home countries. Higher all cause mortality of African men in Portugal contrasts with west African men in the UK (Fig. 2), possibly reflecting the effect of less selective migration because of mass migration from places such as Cape Verde.

Data on ethnic origin are not collected in the census or in death registrations and country of birth was used as a proxy. European ancestry is possible for some of those classified as west African migrants, given that many white Portuguese settled in the excolonies long before independence. This would, however, have weakened the African effect reported here if it is assumed that white Portuguese classified as African migrants would have a 
Fig. 2

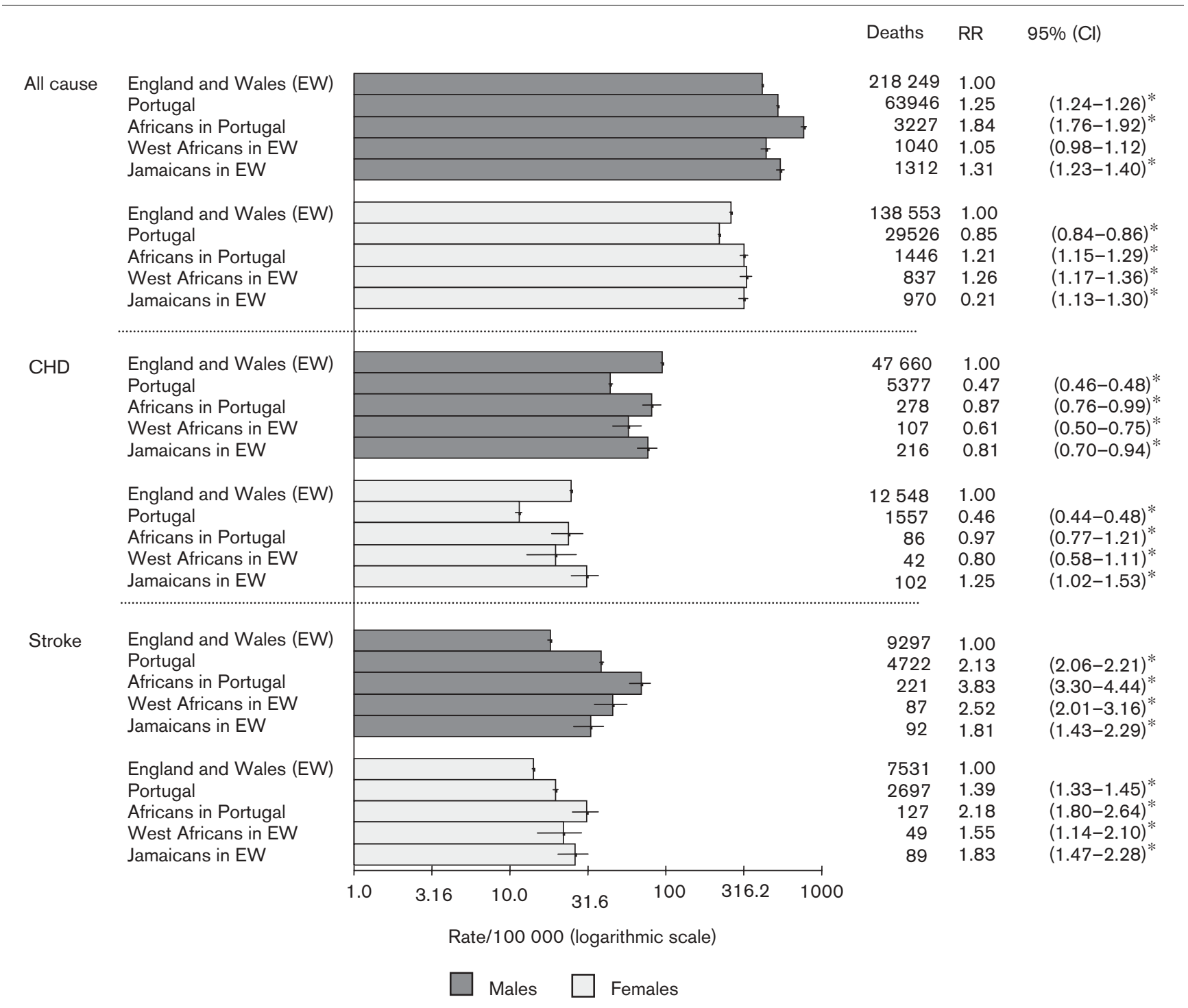

Death rates (rates adjusted to European standard population. $* P<0.05$ compared with rate for those born in England and Wales), rate ratios (RR) and 95\% confidence intervals (Cl) for African origin groups living in Portugal (1998-2002) or England and Wales (1999-2003), aged 25-64 years. CHD, coronary heart disease.

lower mortality risk. The Cape Verdean group is least likely to be affected by this bias.

\section{Conclusion}

Our findings suggest that adverse socio-environmental factors contribute to the relatively high all cause and cardiovascular mortality of African migrants in Portugal.

Health data on migrants are sparse in Portugal and there is an urgent need to ensure the inclusion of relevant data items on ethnicity in national monitoring systems and also for research studies to investigate how best to achieve risk reduction in Africans living there.

\section{Acknowledgements}

Michael Rosato is funded by the Health Research Board (Ireland); other authors by the employing institutions.

Conflict of interest: none.

\section{References}

1 Chaturvedi N. Ethnic differences in cardiovascular disease. Heart 2003; 89:681-686.

2 Cappuccio F, Cook DG, Atkinson RW, Strazzullo P. Prevalence, detection, and management of cardiovascular risk factors in different ethnic groups in South London. Heart 1997; 78:555-563.

3 Cooper R, Cutler J, Desvigne-Nickens P, Fortmann SP, Friedman L, Havlik R, et al. Trends and disparities in coronary heart disease, stroke and other cardiovascular diseases in the United States: findings of the National Conference on Cardiovascular Disease Prevention. Circulation 2000; 102:3137-3147. 
4 Opie L, Seedat YK. Hypertension in sub-Saharan African populations. Circulation 2005; 112:3562-3568.

5 Cooper R, Rotimi C, Ataman S, McGee D, Osotimehin B, Kadiri S, et al. The prevalence of hypertension in seven populations of West African origin. Am J Public Health 1997; 87:160-168.

6 Mackenbach JP, Cavelaars AEJM, Kunst AE, Groenhof F. Socioeconomic inequalities in cardiovascular disease mortality. An international study. Eur Heart J 2000; 21:1141-1151.

7 Santana P. Poverty, social exclusion and health. Soc Sci Med 2002; 55:132-145.

8 World Health Organization. WHOSIS (WHO Statistical Information System) Mortality Data.

9 Pobee JO, Larbi EB, Belcher DW, Wurupa FK, Dodu SR. Blood pressure distribution in a rural Ghanaian population. Trans R Soc Trop Med Hyg 1977; 71:66-72.

10 Oviasu V. Arterial blood pressure and hypertension in rural and urban Cameroon. Int J Epidemiol 1998; 27:181-185.

11 Mokhobo K. Arterial hypertension in rural societies. East Afr Med J 1976; 53:440-444.

12 Mbanya J, Minkoulou E, Salah J, Balkau B. The prevalence of hypertension in rural and urban Cameroon. Int J Epidemiol 1998; 27:181-185.

13 Cappuccio FP, Micah FB, Emmett L, Kerry SM, Antwi S, Martin-Peprah R, et al. Prevalence, detection, management and control of hypertension in Ashanti, West Africa. Hypertension 2004; 43:1017-1022.

14 Cruickshank JK, Mbanya JC, Wilks R, Balkau B, Forrester T, Anderson SG, et al. Hypertension in four African-origin populations: current 'Rule of Halves', quality of blood pressure control and attributable risk of cardiovascular disease. J Hypertens 2001; 19:41-46.

15 Harding S, Rosato M, Teyhan A. Trends for coronary heart disease and stroke mortality among migrants in England and Wales, 1979-2003: slow declines notable for some groups. Heart 2007; doi:10.1136/ hrt.2007.122044.

16 Poulter N, Khaw K, Hopwood B, Mugambi M, Peart W, Sever P. Determinants of blood pressure changes due to urbanization: a longitudinal study. J Hypertens Supp/ 1985; 3 (Suppl 3):S375-S377.

17 Sharma S, Cade J, Landman J, Cruickshank JK. Assessing the diet of the British African-Caribbean population: frequency of consumption of foods and food portion sizes. Int J Food Sci Nutr 2002; 53: 439-444.
18 Lakhani A, Olearnik H, Eayres D. Compendium of clinical and health indicators (2003). London: Department of Health/National Centre for Health Outcomes Development; 2004.

19 Breslow NE, Day NE. Statistical methods in cancer research, volume 2, the design and analysis of cohort studies (IARC Scientific Publications, No. 82). Lyons: IARC; 1987.

20 United Nations, Department of Economic and Social Affairs. Population, Resources, Environment and Development: The 2005 Revision. http://unstats.un.org/pop/dCountryProfiles/CProfile.aspx.

21 Dorling D, Thomas B. People and places: a 2001 Census atlas of the UK Bristol: The Policy Press; 2004.

22 Hardy R, Wadsworth ME, Langenberg C, Kuh D. Birthweight, childhood growth, and blood pressure at 43 years in a British birth cohort 10.1093/ije/ dyh027. Int J Epidemiol 2004; 33:121-129.

23 Byron M. Migration, work and gender. In: Chamberlain M, editor. Caribbean migration: globalised identities. London: Routledge; 1998. pp. 217-231.

24 Marmot MG, Adelstein AM, Bulusu L. Immigrant Mortality in England and Wales 1970-78. OPCS Studies of Medical and Population Subjects. No. 47. London: HMSO; 1984.

25 Harding S, Maxwell R. Differences in mortality of migrants. London: The Stationary Office; 1997.

26 Nazroo JY. The structuring of ethnic inequalities in health: economic position, racial discrimination, and racism. Am J Public Health 2003; 93:277-284.

27 Kaufman JS, Cooper RS, McGee DL. Socioeconomic status and health in blacks and whites: the problem of residual confounding and the resiliency of race. Epidemiology 1997; 8:621-628.

28 Observatório Nacional de Saúde/Instituto Nacional de Estatística (ONSA/INE), Inquérito Nacional de Saúde 2005/2006. Published 2007.

29 Macedo ME, Lima MJ, Silva AO, Alcantara P, Ramalhinho V, Carmona J. Prevalence, awareness, treatment and control of hypertension in Portugal: the PAP study. J Hypertens 2005; 23:1661-1666.

30 Wolf-Maier K, Cooper RS, Banegas JR, Giampaoli S, Hense H-W, Joffres M et al. Hypertension prevalence and blood pressure levels in 6 European countries, Canada, and the United States. J Am Med Assoc 2003; 289:2363-2369.

31 Santana P. Geografias da Saude e do Desenvolvimento. Evolução e tendências em Portugal. Coimbra: Aldemina; 2005. 